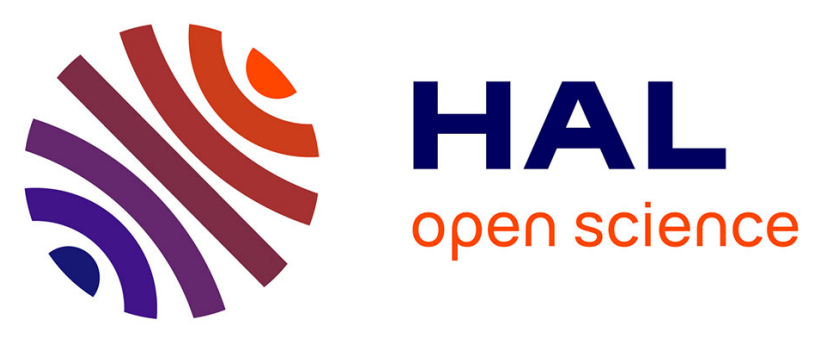

\title{
An Innovative Production Paradigm to Offer Customized and Sustainable Wood Furniture Solutions Exploiting the Mini-Factory Concept
}

Paolo Pedrazzoli, Franco Antonio Cavadini, Donatella Corti, Andrea Barni, Tommaso Luvini

\section{To cite this version:}

Paolo Pedrazzoli, Franco Antonio Cavadini, Donatella Corti, Andrea Barni, Tommaso Luvini. An Innovative Production Paradigm to Offer Customized and Sustainable Wood Furniture Solutions Exploiting the Mini-Factory Concept. IFIP International Conference on Advances in Production Management Systems (APMS), Sep 2014, Ajaccio, France. pp.466-473, 10.1007/978-3-662-44736-9_57 . hal-01387918

\section{HAL Id: hal-01387918 \\ https://inria.hal.science/hal-01387918}

Submitted on 26 Oct 2016

HAL is a multi-disciplinary open access archive for the deposit and dissemination of scientific research documents, whether they are published or not. The documents may come from teaching and research institutions in France or abroad, or from public or private research centers.
L'archive ouverte pluridisciplinaire HAL, est destinée au dépôt et à la diffusion de documents scientifiques de niveau recherche, publiés ou non, émanant des établissements d'enseignement et de recherche français ou étrangers, des laboratoires publics ou privés. 


\title{
An innovative production paradigm to offer customized and sustainable wood furniture solutions exploiting the mini-factory concept
}

\author{
Paolo Pedrazzoli*, Franco Antonio Cavadini**, Donatella Corti*, Andrea Barni*, \\ Tommaso Luvini* \\ *University of Applied Sciences and Arts of Southern Switzerland, ISTePS, Manno, Switzer- \\ land \\ \{donatella.corti, luca.canetta, alessandro.fontana\} @supsi.ch \\ * * Synesis, Lomazzo, Italy \\ franco.cavadinilsynesis-consortium.eu
}

\begin{abstract}
To face increasing competitive pressures, European industry must develop methods and enabling technologies towards a personalized, customer oriented and sustainable manufacturing. This statement is well understood by many companies, shared by policy maker at the European Commission (e.g. as per the "Factory of the Future" multi-annual road-map), and empowered by the current funding programmes for industrial research (Horizon2020). Manufacturers are demanded to merge the need to be reactive towards customer needs and wishes (customized products), with the requisite to be proactive towards ecological and social impact (sustainable products). This concept points out two key elements whose impact on manufacturing is complex and interdepended: Customization and Sustainability. Within the CTC 3-year project methods and innovative enabling technologies are developed and integrated to enable a local flexible manufacturing of green personalized furniture close to the customer.

Keywords: furniture sector; mini-factory; short supply chain; green label; customization
\end{abstract}

\section{Production system innovation in the furniture sector}

Europe is a major player in furniture on a global scale, with a total of more than 151.000 companies of which $95 \%$ are SMEs. Despite increasingly fierce global competition and significant relocation of manufacturing to low-wage countries, furniture continues to represent one of Europe's major industrial sectors with an annual turnover of more than 130 Billion Euro, and a total workforce of 1,4 million. Manufacturers in this sectors have 1) to become more agile and flexible, in response to the fast rate in which market trends change, demanding manufacturing infrastructures that can produce higher variations in smaller quantities and 2) to introduce personalized products and services whose added value can trigger market acceptance. In this framework, environment intangibles (such as environmental pollution, waste and energy consumption) are also recognized as urgent and the furniture sector faces the chal-

adfa, p. 1, 2011.

(C) Springer-Verlag Berlin Heidelberg 2011 
lenge to actively consider and control those factors as well. This is because both customers demand sustainable products and governments are willing to sharpen regulations to commit companies to improve.

An innovative production paradigm aimed at supporting the European Industry to adapt to global competitive pressures is being developed by the European-funded project CTC. Within this the three-year project started in 2013, methods and innovative enabling technologies are developed and integrated to enable a local flexible manufacturing of green personalized products close to the customer in terms of features offered, place of fabrication, time to deliver, and cost. The integration of sustainability and customization issues is a promising strategy as stressed in recent works (e.g. [1]). This vision is implemented and demonstrated within a European industrial sector of excellence: the furniture sector. The ultimate implementation envisions a "green factory behind a glass pane" directly in the shopping mall, where the customer witnesses the manufacturing of its personalized furniture.

In this paper the foreseen system and its impacts are described. First, the pillars the new production paradigm will be based on are introduced highlighting how they go beyond existing solutions. Then, an overview of the foreseen mini-factory layout and functioning is described before presenting the actors who will interact with it. Expected impacts of the proposed concept are discussed before drawing conclusions.

\section{The production paradigm's pillars}

Main pillars shaping the new production paradigm and their corresponding innovativeness are summarized in the following points:

Formalized Design Approach (and related software technologies) to empower "design to manufacturing in one step" (which also includes the design finalization carried out by the customer himself). The development of a formalized furniture design approach refers to the tools and engineering methods to make the design seamlessly compatible with the manufacturing phase (fostering a design approach standardization), and must not be mistaken for the imposition of a common design style: distinctiveness of styles must be preserved as a key added value. CTC tools are meant to approach product design from a holistic perspective, integrating design methodologies in plug in software for currently available technologies in the woodworking sector. The integration of 3DCE and DfX methodologies promoted by CTC in current software tools and the reduction of complexity in the transition from CAD to CAM will foster a simplified approach to product definition according with an efficient product manufacturing. Starting from the analysis of the state-of-the-art in design methodologies ([2]; [3]; [4]; [5]) and tools (e.g. [6] and [7] for configurators), a process will be developed allowing the simultaneous generation of product design and reliable manufacturing data leading to a $50 \%$ reduction of "design to production" time of $50 \%$ and a $80 \%$ reduction of the time to market for new products development.

Mini-factory Production System Model that can be easily and quickly instantiated in local green factories, and whose processes and machines can be driven directly by the formalized design process. This model represents the factory "to be" blueprints, its 
logistic structure and short JIT supply chain management approach that takes into consideration existing example of mini-factory (e.g. [8]). It can be regarded as the basis for the "factory franchising" concept, where the manufacturing system can be instantiated locally with minimal production design effort. Thanks to this new system a $60 \%$ decrease in throughput time in production is expected as well as an increased ability to rapidly follow market by means of fast production and delivery of customised furniture. Reduced environmental impact because of no unsold or long term storage of products and reduction of work in progress thanks to smart order management and responsive supply chain are also interesting improvements from both economic and sustainable point of view.

Woodwork machining system able to empower the "Close to the Customer" concept. Main target is the development of a next generation woodworking system with high flexibility, high safety standards and ease of use with low production cost and low environmental impact, in particular for very small batches and JIT production, ultimately delivering very quickly to the customer. The system will be empowered by advanced HMI control and automatic machine set-up, and will then run continuously as in flow- like production. As the factory is meant to be instantiated "close to the customer", the machining system must specifically tackle issues such as dust extraction and noise control. Technological advances will allow the achievement of a reduction of $\mathrm{CO} 2$ emissions, lower training time and a safer working environment.

A CTC Green Label in order to bring to customer awareness of the uniqueness and advantages of the production process, based on ISO 14955 extension to woodworking machines and on the FSC (Forest Stewardship Council), a certificate label will be developed. The label, also taking advantage of the development of a proper assessment model, is meant to be recognizable and unified, but still articulated and capable of highlighting local peculiarity.

The most challenging aspect of the CTC project is the need for a deep integration between the different modules that expose its multifaceted functionalities. The focus of the validation and demonstration activities will be therefore towards an effective integration of all CTC reference framework modules, because it is in their completed coordination that resides the success of the project. If any of the composing elements is innovative in of its specific characteristics, it is the coordinated effort for creating a much shorter production chain that really transforms the mini-factory into a major technological breakthrough. The success of the proposed production paradigm will be thus based on the exploitation of the above-mentioned innovations, but, above all, from the integration of all of them in an innovative business model delivering value through a local flexible manufacturing of green personalized products close to the customer. The economic potential of this concept lays in the possibility of instantiating several mini-factories all over Europe creating a franchising network.

\section{The reference architecture}

The foreseen functioning of a CTC mini-factory is introduced to give an idea of how the innovative elements will be interacting with each other to enable production 
and sale of sustainable and customized pieces of furniture close to the customers. The description tells how the CTC mini-factory will look like to a potential visitor once it will be running. Peculiarities of the CTC system at both factory and supply chain level are pointed out to provide an overview of what are the envisioned results upon project completion. A schematic representation of what is being presented is shown in Figure 1. The CTC mini-factory finds its ideal location in a shopping mall where both the sales area (CTC-shop) and the production area (CTC-factory) are located next to each other and are accessible by people visiting the mall. The CTC-system gets started when the Customer enters the CTC-shop and, with the support of a trained CTCoperator, customizes the furniture he/she is interested in using a user-friendly configurator. The design of furniture is driven by a parametric portfolio of products that has been predefined by CTC designers coherently with the functional constraints of the mini-factory. Once the furniture project (a single piece of furniture or a complete room) is finalized and the customer is satisfied with the offer, an order is generated and sent to the CTC-factory. Machine instructions are automatically created to command the behavior of the mini-factory. A real-time update of production data allows the customer to monitor the processing status of his/her order other than to increase the efficiency of the production system itself. A high level of integration of informative systems is one of the main features the CTC-system will rely on. In fact, a smooth flow of information from the idea generation to the production will allow a lean fulfillment of orders in short times. The details of the factory have to be carefully designed along with the supporting supply chain and material handling system. The idea is to have a short supply chain in order to favor the creation of a local suppliers base and to keep the level of inventories within the factory as low as possible. Raw material suppliers will be constantly managed by CTC mini-factory, coherently with short-term planning of the production, in order to grant adequate replenishment of stocks. Strong agreements with fast couriers are exploited for quick logistics. In so doing, a small inbound warehouse able to cover the needs of a few orders is enough. An automated warehouse will be set up in this place so that raw materials (panels) will be moved directly to the production line coherently with the production plan. At the end of the production line a packaging area is setup that will act also as outbound warehouse. So at this point the material is ready to be collected by local couriers for fast delivery to the customer. For the assembly phase, the idea of the project, is to leave the customer the possibility to choose between a specialized operator or the kit for Do-It-Yourself. Finally, it is worth of mention the attention that in the CTCsystem it will be paid to the waste management. Production waste has to be managed in a life-cycle conscious way, considering main potential way of treatment: re-cycled through direct agreement with raw material suppliers, burnt for energy generation, or sent to local landfills. To sum up it can be said that a compact and lean system is envisioned that will guarantee the achievement of excellent performance in terms of both customer service (short delivery time and high level of customization) and production efficiency. The design of a proper supply chain is important as well to reach this level of performance. 


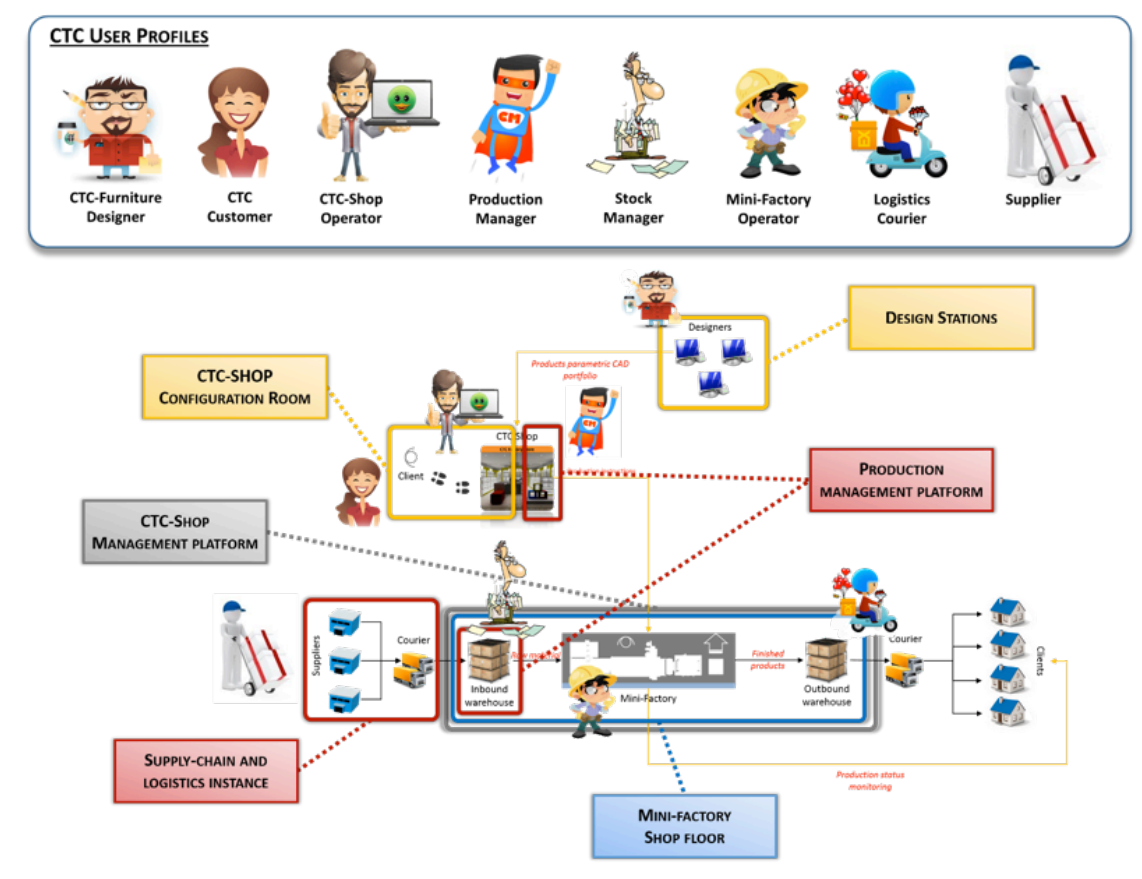

Figure 1: Reference architecture of the CTC mini-factory, and corresponding users.

\section{The CTC users}

Complementary to the innovative modules of CTC, and taking into account that they become the principal interface between the mini-factory as a system on one side, and its users on the other one, a certain set of "CTC user profiles" has been defined. These roles have been selected as those strictly necessary for the good operation of the mini-factory. They are:

- $\quad$ The CTC-Furniture Designer, who will prepare the parametric product portfolio;

- The CTC Customer, interacting with the mini-factory to obtain a customized furniture element;

- The CTC-Shop Operator, interacting with the customer for the product design;

- The Production Manager, supervising the whole mini-factory;

- The Stock Manager, specialized in managing inventory;

- The Mini-factory Operator, capable of operating the whole shop-floor;

- The Logistics Courier, to grant fast delivery of packages;

- The Supplier, to create a really short and integrated supply chain.

The term "user profiles" has been adopted because it is not conceived to represent the physical people who will interact with the CTC pilot, but the roles needed to make the factory work. 


\section{$4 \quad$ Impacts generated by the implementation of the concept}

The basic idea of CTC is to move the factory directly where the customer is used to shopping: a green mini-factory is set up behind a glass pane in the shopping mall. The main target of the project is a customer segment with an average money availability who is willing to pay for a higher level of customization and who is aware of sustainability issues. The type of selected items and the location of the factory make the young and middle-aged people with children the most interested customers category. The pilot mini-factory will offer pieces of furniture for bedrooms for children and living rooms. The business model behind the diffusion of the CTC mini-factory is based on the idea that the same factory model is installed in shopping malls in different European countries. Local tastes and needs can be taken into account when the product is designed in the point-of-sale, yet the production system is a common one (not its supply chain, though). As a whole, expected benefits from the CTC project will have a significant impact on the European economy, also considering the high number of involved actors in the sector. Implementation of the CTC Mini-Factory will have a major impact on the wood furniture sector for both customers and manufacturers: the creation of a franchising network, for example, could reshape the traditional supply chain and leading to benefits not only in economic terms, but also from the sustainability perspective. The mini-factory is characterized by a set of machines and equipment strictly close to each other not only for the physical proximity, but also from the management point of view. The factory can work without work-in-progress since single orders are moved along the production system. The level of automation is high: the design software is linked with the production resources and the working instructions are automatically sent to machines that are reconfigured automatically with almost null setup times. The system thus works continuously avoiding time losses due to non-productive times - like queues or set ups- that are typical in the current production environment of this sector. The level of embedded technology is so advanced that in the best performing mini-factory a single operator is needed to run the whole system and he does not need to be skilled. In order for the operator to monitor the system, it will be possible to rely on a centralized control panel that do not requires specific knowledge of the single machine. Such configuration of the production system will allow the promising short delivery times (48 hours) and the offer of high level of level of customization.

The initial investment to set up one CTC mini- factory is expected to vary from a minimum of 330.000 Euro and a maximum of 580.000 Euro. In an IKEA shop, the price for a set of pieces of wooden furniture for a living room including TV and media furniture combined with storage units, a bookshelf, a desk and a coffee table could range approximately between 350 and 1900 Euro. A reasonable price for a living room offered under the CTC label should be around 2500 Euro.

A possible average price for a CTC bedroom for children including one single bed, a desk, one armoire with 3 doors, 2 shelves, a bookshelf and a chest of drawers could be set equal to 2000 Euro, whilst a rough estimation for a living room offered under the CTC label including TV and media furniture combined with storage units, a bookshelf, a desk and a coffee table should be around 2500 Euro. 


\section{A network of mini-factory}

The CTC mini-factory finds its ideal location in the European shopping malls. The evolution of the European retail environment calls for more shopping centre space in the near future: it was estimated by Experian [9] that the retail industry would have been the third fastest growing industry between 2005 and 2016 with an average growing rate of $2.6 \%$ per year. Considering both their current base and the developing potentialities, the malls can be considered as a fertile ground for the propagation of the CTC mini-factory production model in Europe. The selection of the location for installing the first mini-factories is crucial to get the expected results. Italy, UK and France are the best candidates: their high number of shopping malls [10] is a proof that customers are more used to visit shopping malls and are probably more enthusiastic to experience shopping-related novelties.

In order to identify a reasonable numbers of mini-factories in the hypothetical franchising network that could make the business model a profitable and successful one, the main chains competing in the consumer "do-it-yourself" market sector at the European level have been used as a reference point (i.e. Bricocenter, Leroy Merlin, Obi center, Castorama). On the one hand, the production and delivery mode used by the CTC concept is unique: companies considered as competitors in terms of product types and volumes use different sale channels and their network structure couldn't represent a valid reference. On the other hand, the choice of basing the factory in the shopping mall makes it necessary to take into consideration features characterizing the retail world and their adaptation to the CTC concept. Using the specialized chains based on the "do-it-yourself" mode seems a good choice since, though their offer is based on catalogues, it could be assumed that their customers share some interests with the ones targeted by the CTC mini-factory. Customers who like the "do-ityourself" products pay attention to the sustainability aspect and are willing to spend time to choose single components and to put their own efforts to get the product that at the best fits with their needs. Considering the level of diffusion of the "do-ityourself" chains in Europe and assuming that the CTC mini-factory network will be, at least in the medium term, it is reasonable to assume that, in 5-year time, an overall number of 150-180 CTC mini factories will be operating in different European countries. The opening of an average of 30 centres per year is aligned with the expected efforts to install a new mini factory. The overall expected economic impact can be quantified approximately in $360 \mathrm{mln}$ Euro of early turnover generated by a minifactory network of 150 units. This value corresponds to a $3 \%$ market share in value of the European market for the two segments of interest (bedrooms and living rooms). This esteem is likely to underestimate the business of the mini-factory since a smart capacity management policy could generate additional turnover by saturating the available capacity producing pieces of furniture for third parties. Widening the scope, a less easily quantifiable, yet important, business volume is induced in the supply chain. In this phase of the analysis it is not possible to provide precise values, but, for sure, it will contribute to amplify the CTC impact at the European level. 


\section{Conclusion}

This paper first provided an overall understanding of a new paradigm in furniture production, based on the local flexible manufacturing of green personalized furniture close to the customer in terms of features offered (customization), place of fabrication (mini-factory in the shopping-mall), time to deliver (logistics arrangements), and cost (from customization to mass-customization). It then focused on the impact that such a paradigm will have on European economy once implemented. While still enduring fierce competition and relocation, Europe is nonetheless a major player in furniture on a global scale, where personalization and sustainability will represent a key strategy for its future development and success. Whereas the CTC paradigm is implemented and tested in the wood-working sector, the project consortium firmly believes that new business solutions meant to empower consumers as designers, manufacturers to produce in a distributed and small scale manner, and suppliers to be more flexible and demand-driven will be mandatory for most European industrial sectors.

\section{References}

1. Boër, C.R., Pedrazzoli P., Bettoni A., Sorlini, M. (2013). "Mass Customization and Sustainability. An assessment framework and industrial implementation.",Springer.

2. Herrmann J.W., Cooper J., Gupta S. K., Hayes C.C:, Ishii K., Kazmer D., Sandborn P.A., Wood W.H. (2004) New directions in design for manufacturing. Salt Lake City, Utah USA. ASME 2004 Design Engineering Technical Conferences and Computers and Information in Engineering Conference.

3. Ellram L.M., Tate W.L., Carter C.R. (2007) Product-process-supply chain: an integrative approach to three-dimensional concurrent engineering.. International Journal of Physical Distribution \& Logistics Management, Vol. 37.

4. Addo-Tenkorang, R. (2011) Concurrent Engineering (CE): A Review Literature Report. San Francisco, USA. Proceedings of the World Congress on Engineering and Computer Science, Vol II, 2011.

5. Tolouei-Rad, M. (2006) An approach towards fully integration of CAD and CAM technologies, Journal of Achievements in Materials and Manufacturing Engineering, Vol.18, No.1-2, pp. 31-36.

6. Walcher, D. and Piller, F. (2012) The customization 500 - An international Benchmark Study on Mass Customization and Personalization in Consume E-Commerce.

7. cyLEDGE-Media, GmbH. Configurator Database. Configurator-Database. [Online] [Cited: 2011 2012.] http://www.configurator-database.com/.

8. Jackson, M. and Zaman, A. (2006) Factory-In-a-Box - Mobile Production Capacity on Demand.. IJME - INTERTECH Conference, 2006. ENT 104-045.

9. ESCT The importance of shopping centres to the European economy, March 2008. (http://www.icsc.org/srch/rsrch/wp/FINAL_Mar08_Complete\%20WITH\%20new\%20cove r\%20and\%20charts\%20and\%20tables.pdf )

10. Lambert, J. (2006) One step closer to a pan-European shopping enter standard, Research Review, Vol. 13, No, 2 (http://www.icsc.org/srch/lib/euro_standard_only.pdf) 